\title{
Trajetórias de mulheres privadas de liberdade: práticas de cuidado no reconhecimento do direito à saúde no Centro de Referência de Gestantes de Minas Gerais
}

\section{| ${ }^{1}$ Tatiana Coelho Lopes, ${ }^{2}$ Roseni Pinheiro |}

Resumo: Objetivo: Analisar a trajetória de cuidado de mulheres de um Centro de Referência a Gestantes Privadas de Liberdade (CRGPL), no que concerne às práticas dos trabalhadores no reconhecimento do direito à saúde e integralidade do cuidado. Metodologia: Adotaram-se a fenomenologia sociológica e a teoria do reconhecimento proposta por Alex Honneth (2003). Entrevistaram-se mulheres, agentes penitenciárias, diretores do CRGPL e do Hospital Sofia Feldman e profissionais de saúde, sendo realizada observação direta. Resultados e discussão: Identificaram-se três planos de reconhecimento, sendo que a autoconfiança foi verificada nas relações de vínculo e acolhimento dessas mulheres por gestores e trabalhadores. $\mathrm{O}$ autorrespeito foi identificado no entendimento, de profissionais e gestores, de que essas mulheres perderam seus direitos civis, mas que a saúde como um direito deve ser garantida. Verificou-se a autoestima na rede de solidariedade e compromisso construída de forma que resolutividade, referência e contrarreferência dessas mulheres sejam capazes de garantir o direito e a integralidade do cuidado. Conclusões: $\mathrm{O}$ estudo busca dar visibilidade a formas de cuidado mais solidárias, em que a garantia à saúde e ao cuidado integral não sejam apenas o cumprimento de um direito individual, mas uma nova forma de tratar essa questão na sociedade.

> Palavras-chave: gravidez; prisão; integralidade.
1 Hospital Sofia Feldman. Belo Horizonte-MG, Brasil (tatianacoelholopes@gmail. com).

2 Instituto de Medicina Social, Universidade do Estado do Rio de Janeiro. Rio de Janeiro-RJ, Brasil (rosenisaude@uol.com.br). 


\section{Introdução}

Este artigo visa contribuir para discussão sobre as práticas de cuidado vivenciadas por mulheres em situação de privação de liberdade, a partir de um estudo de natureza empírica, de caráter exploratório, sobre suas trajetórias no sistema prisional do Estado de Minas durante a gestação, parto e pós-parto.

Para dar início a essa discussão, partimos de dados sobre essa população no contexto nacional. O Brasil é o quarto país de maior população carcerária no mundo. Cerca de 700 mil de seus 190 milhōes de habitantes estão em situação de reclusão em estabelecimentos penais, o que torna o tema da saúde no sistema prisional um dos mais importantes na definição de prioridades de pesquisa na Saúde Coletiva (SILVA, 2015).

De acordo com o Ministério da Saúde, o número de mulheres em situação de prisão tem crescido nos últimos anos, sendo que no ano de 2000 representavam 5\% da população prisional e, em 2010, 12\% (BRASIL, 2010). Quando se consideram as questôes de gênero, três quartos dos estabelecimentos prisionais são destinados à população masculina, e apenas 7\% são exclusivos da feminina (BRASIL, 2014a).

A exclusão social vivida por essas mulheres (CARVALHO et al., 2006), associada a outras questōes, como vulnerabilidade ${ }^{1}$ (CEJIL et al., 2007; BRASIL, 2008) e invisibilidade - por estarem ausentes de espaços públicos (CARVALHO et al., 2006; MIYAMOTO; KROHLING, 2012) - tem sido bastante enfatizada nas discussões sobre o cotidiano das pessoas que vivem dentro do sistema prisional, cujas especificidades se concentram nas relações de gênero quando se considera especificamente a população carcerária feminina (MINZON; DANNER; BARRETO, 2010; MIYAMOTO; KROHLING, 2012; CARVALHO et al., 2006).

Segundo o relatório do Grupo de Trabalho Interministerial da Secretaria Especial de Políticas para as Mulheres, o perfil das mulheres encarceradas no país é composto por jovens, mães solteiras e afrodescendentes (BRASIL, 2008). Apenas $14 \%$ delas completaram o ensino médio e $63 \%$ foram condenadas por tráfico de drogas (BRASIL, 2014a), sendo esta a principal causa para o aumento de mulheres presas nos últimos anos (GOIS et al., 2012).

É de conhecimento que o sistema penitenciário brasileiro apresenta deficiências estruturais, que reforçam a cultura da violência institucional, fomentando 
práticas e abordagens discriminatórias e violentas, ferindo a dignidade e violando direitos humanos (BRASIL, 2008; RODRIGUES, 2008; CJDI et al., 2007). Essa situação se estende aos filhos das mulheres privadas de liberdade e acaba por reproduzir um círculo vicioso persistente de violação dos direitos humanos (VENTURA; SIMAS; LAROUZÉ, 2015).

Deve-se considerar o processo histórico no qual os estereótipos de gênero são reforçados dentro do sistema prisional, já que as primeiras instituições penais femininas no país foram vinculadas a ordens religiosas como espaços de "purificação" das mulheres criminosas (JESUS; LERMEN, 2003).

Segundo o relatório sobre a realidade das mulheres encarceradas no Brasil conduzido pelo Centro pela Justiça e pelo Direito Internacional (CJDI) e outras entidades:

[...] a mulher encarcerada no Brasil é submetida a uma condição de invisibilidade, condição essa que, ao mesmo tempo em que é sintomática, "legitima" e intensifica as marcas da desigualdade de gênero à qual as mulheres em geral são submetidas na sociedade brasileira, sobretudo aquelas que, por seu perfil socioeconômico, se encontram na base da pirâmide social, como é o caso das encarceradas. (CJDI et al., 2007, p. 6-7).

A exclusão extrema vivida pelas pessoas nessa situação está integrada por processos de vulnerabilidade, fragilização, precariedade e ruptura dos vínculos sociais nas dimensões econômicas, ocupacionais, sociofamiliares, de cidadania, das representações sociais e da vida humana (CARVALHO et al., 2006). No caso das mulheres, essa mesma situação é agravada pela conformação dos papéis sociais exercidos por homens e mulheres, que acentuam a dominação da mulher pelo homem e no quais as diferenças biológicas servem como fundamento para a naturalização da divisão dos papéis sociais desempenhados por ambos.

Dessa forma, os processos de ressocialização das mulheres estão associados a atividades consideradas "femininas" como artesanato, culinária ou atividades de apoio ao estabelecimento penal (MIYAMOTO; KROHLING, 2012), ao mesmo tempo em que, muitas vezes, seus desejos e sua sexualidade são denegados, quando as visitas íntimas não são permitidas nos estabelecimentos femininos (ANDRADE, 2004).

No que tange ao cuidado em saúde de mulheres privadas de liberdade, é importante destacar a Lei de Execução Penal (BRASIL, 2009) e as Resoluções (CONSELHO NACIONAL DE POLÍTICA CRIMINAL E PENITENCIÁRIA, 2003) que asseguram às mulheres presas e a seus recém- 
nascidos condições mínimas de assistência que deverão iniciar-se desde seu ingresso no sistema penitenciário.

No que se refere às políticas interministeriais, o Plano Nacional de Saúde no Sistema Penitenciário (PNSSP) preconizava que o acesso das pessoas presas ocorresse de forma integral e efetiva (BRASIL, 2005), com várias estratégias relacionadas mais especificamente à saúde. Em 2014, a Política Nacional de Atenção Integral à Saúde das Pessoas Privadas de Liberdade no Sistema Prisional (PNAISP), instituída no âmbito do SUS, destacava o respeito aos direitos humanos e à justiça social e a integralidade da atenção à saúde da população privada de liberdade no conjunto de ações de promoção, proteção, prevenção, assistência, recuperação e vigilância em saúde, executadas nos diferentes níveis de atenção. Para isso, preconiza-se a necessidade de integração à Rede de Atenção à Saúde do território com equipes de Saúde Materno-Infantil nas unidades que custodiam mulheres e a garantia da qualidade pela Rede Cegonha (BRASIL, 2014b).

O Estado de Minas Gerais contém a segunda maior população prisional do país, com 61.286 presos, 184 estabelecimentos prisionais e uma taxa de encarceramento que segue um ritmo acelerado, com aumento de 163\%, quando comparado ao Brasil, que foi de 66\%, entre os anos de 2005 a 2014 (BRASIL, 2014a).

$\mathrm{O}$ Centro de Referência à Gestante Privada de Liberdade (CRGPL) foi inaugurado pelo governo do estado de Minas Gerais em janeiro de 2009, com o objetivo de permitir que as mães presas ficassem com seus filhos até eles completarem um ano de idade (MINAS GERAIS, 2011). Atualmente, todas as mulheres grávidas no sistema prisional daquele estado são transferidas para o CRGPL no sexto mês de gravidez. A unidade tem administração pública e foi alocada em um espaço alugado que abrigava uma clínica de saúde mental na cidade de Vespasiano. Essa é uma realidade nacional que foi evidenciada pelo relatório do CJDI e colaboradores (CJDI et al., 2007), pela CPI penitenciária (BRASIL, 2009) e pelo grupo formado pela Secretaria Especial de Políticas para as mulheres (BRASIL, 2008): os prédios ocupados por mulheres no sistema carcerário quase sempre são reformados, geralmente sem observar as especificidades delas; muitas vezes, são construções públicas que foram desativadas ou interditadas por questōes de segurança ou salubridade. Desde sua inauguração, realiza-se uma parceria entre o CRGPL e o Hospital Sofia Feldman (HSF), inicialmente para assistência ao pré- 
natal de risco habitual e parto, que depois avançou para o acompanhamento dos cuidados com os recém-nascidos (COUTINHO et al., 2015).

Considerando o princípio da integralidade presente nos programas e políticas voltados à população privada de liberdade, recorremos às contribuições ao seu constructo teórico na Saúde Coletiva, na qual ela é entendida como uma ação social resultante da interação democrática dos sujeitos, em planos distintos de atenção à saúde, permeados por espaços de exercício de poder, constituindo práticas sociais, influenciadas por práticas sanitárias e políticas (PINHEIRO, 2001). O direito à saúde, a partir do referencial da integralidade, é concebido como o direito de ter acesso universal aos cuidados em saúde, com os recursos necessários e qualidade. Mas, para além do acesso, o direito à saúde também é direito de ser, ou seja, um direito de ser diferente, de ser respeitado em sua alteridade, o que implica uma ampla luta contra qualquer espécie de preconceitos e estigmas (PINHEIRO, 2007; 2010).

$\mathrm{O}$ acesso e os cuidados em saúde das mulheres privadas de liberdade constituem uma questão relevante na discussão acadêmica, seja pelas relações de poder reproduzidas nos espaços privados dentro do sistema prisional, seja pela não possibilidade de acesso aos serviços por vontade própria pelo cumprimento da pena. Assim, são necessários mais esforços para colocar em prática esse princípio, por se tratar de direitos garantidos pelas mulheres e seus filhos. O resgate da cidadania e da saúde dessa população é emergencial; para Ventura, Simas e Larouzé (2015), o primeiro passo está relacionado à necessidade de dar visibilidade à questão da maternidade e das crianças em situação de encarceramento, bem como ao reconhecimento e a garantia dos direitos reprodutivos e parentais.

Dessa forma, torna-se pertinente analisar as experiências sobre o cuidado dessa população, na perspectiva da integralidade, que considerem sua própria condição de confinamento como uma oportunidade para compreender a construção de projetos terapêuticos, açóes preventivas e educativas voltadas para sua necessidade, como forma de reconhecimento da sua cidadania.

\section{Metodologia}

Trata-se de uma pesquisa qualitativa que tem como referencial a fenomenologia sociológica (SCHUTZ, 1979). Para a análise das trajetórias de cuidado das mulheres no contexto de exclusão e vulnerabilidade que se encontram no sistema prisional, 
1198 buscamos na teoria do reconhecimento proposta por Alex Honneth (2003) e na releitura de Martins (2009) e Miranda, Rivera e Artmann (2012), subsídios para pensar a multiplicidade de mecanismos de construção do reconhecimento.

ParaHonneth (2003), os sujeitos são forjados em suas interações e só conseguirão formar uma autorrelação positiva caso se sintam reconhecidos por seus parceiros de interação. $\mathrm{O}$ autor constrói uma trilogia necessária para o reconhecimento dos sujeitos, que envolve três planos: a autoconfiança que buscamos nas relaçōes de amor $^{2}$ e afetividade; o autorrespeito que adquirimos nas relaçôes de direito na esfera político-jurídica; e a autoestima que pretendemos obter nas relaçôes de solidariedade nas esferas civil e pública (HONNETH, 2003). No campo da Saúde Coletiva, Martins (2009) faz uma releitura desses planos na perspectiva da visibilidade dos usuários no sistema de saúde e Miranda, Rivera e Artmann (2012), na perspectiva do trabalho interdisciplinar nos serviços de saúde. Dessa forma, pareceu-nos evidente que a busca por reconhecimento mantém uma relação intrínseca com o processo de organização, tanto imaginária como institucional, do ser usuário em espaços públicos de cuidado no sistema prisional. Acreditamos que o referencial do reconhecimento possibilita identificar ao mesmo tempo, as perspectivas individual e coletiva, como elementos de dependência recíproca, já que se trata de uma construção do sujeito que depende de um contexto social e que pode conter atributos de integralidade quando consideramos as relações intersubjetivas presentes no cuidado das mulheres privadas de liberdade.

Como técnica de coleta de dados, foi aplicada uma entrevista semiestruturada com as pessoas envolvidas no contexto de estudo: mulheres privadas de liberdade, agentes penitenciárias, diretores do Centro de Referência à Gestante Privada de Liberdade (CRGPL) e do Hospital Sofia Feldman (HSF) e profissionais de saúde de ambas as instituições. Outra técnica utilizada foi a observação direta, cuja aplicação se deu em momentos de encontros entre as direções do HSF e CRGPL sobre questōes pertinentes ao cuidado das mulheres privadas de liberdade.

O período de coleta aconteceu no mês de janeiro de 2014 e nos meses de setembro e outubro de 2015. A realização da coleta nesses dois momentos foi importante para acompanhar a perenidade das açōes desenvolvidas no que se refere ao cuidado das mulheres e seus filhos privados de liberdade, assim como as açõos conjuntas realizadas pelas instituições. Durante a realização das entrevistas, tanto dos profissionais como das mulheres privadas de liberdade, foi solicitado que 
descrevessem as relações necessárias para o cuidado dessas mulheres e seus filhos na perspectiva da integralidade. Para apreensão desses elementos, utilizamos a construção da trajetória de cuidado (PINHEIRO; SILVA JUNIOR, 2011) como recurso metodológico analítico, que considerou como ponto de partida a entrada no sistema prisional e/ou o momento de identificação da gravidez.

Participaram das entrevistas profissionais das duas instituições: no CRGPL, diretora, psicóloga, técnica de enfermagem, uma agente prisional e duas mulheres privadas de liberdade; no HSF, o diretor, enfermeira obstetra e uma terapeuta ocupacional.

É importante destacar que, no CRGPL, é proibida a entrada de dispositivos de gravação, então as entrevistas com as mulheres e os profissionais (diretora e agentes penitenciários) nesse local foram registradas com o apoio de uma pesquisadora por meio de notas, sendo digitadas logo após a visita. O critério de escolha das duas mulheres entrevistadas se deu em função de dois aspectos contextuais: primeiro, a definição pela diretora sobre qual mulher teria disponibilidade de participar no momento de ida da pesquisadora e o segundo, a permanência da mulher no CRGPL por um período de pelo menos um mês antes da pesquisa. No momento da entrevista, foi permitido que elas permanecessem com mais privacidade em uma sala com a pesquisadora, enquanto as agentes realizavam a segurança do lado de fora. A porta foi mantida aberta, mas sem supervisão direta das agentes penitenciárias. Com os profissionais do Hospital, as entrevistas foram gravadas e posteriormente transcritas.

Quanto aos aspectos éticos, o projeto observou as recomendações determinadas pelo Comitê de Ética em Pesquisa do Hospital Sofia Feldman (CAAE: 41523415.3.0000.5132), sendo autorizada sua realização pela Secretaria Segurança de Defesa Social do Estado de Minas. Todos os preceitos definidos pela Resolução no 466/2012, do Conselho Nacional de Saúde foram considerados. O termo de consentimento livre e esclarecido foi apresentado às mulheres e aos profissionais, para realização das entrevistas. Nomes fictícios foram adotados para manter o anonimato dos participantes.

O material foi organizado a partir da sistematização do que foi produzido na reunião entre os diretores das duas instituições, assim como as anotações realizadas durante as entrevistas no CRGPL e das transcrições das entrevistas com os profissionais do HSF. No primeiro momento, foram retiradas 

segundo momento, foi realizada uma leitura em profundidade com o escopo de mapear as redes de relações estabelecidas na organização dos serviços de saúde e prisional, com vistas a garantir o cuidado prestado às gestantes privadas de liberdade na perspectiva da integralidade.

\section{Resultados e discussão}

Observou-se, nas trajetórias das duas mulheres privadas de liberdade entrevistadas, que a situação de vulnerabilidade social antecede ao período de seu encarceramento. Essa nova situação é perpetuada, impondo uma fragilização ainda maior dos vínculos familiares

Joana tem 30 anos, solteira. Sua família reside em uma outra cidade da região metropolitana. Foi presa com 26 semanas de gestação passou por uma Delegacia do Departamento de Operações Especiais (DEOESP). Essa gravidez é de seu sétimo filho. Ia fazer uma laqueadura tubária [método contraceptivo de difícil reversão] no ano passado, mas se envolveu com drogas novamente. Em dezembro de 2014, ganhou alvará de soltura. Em julho de 2015, foi presa novamente por causa do crack e autuada pelo artigo 33. Trabalhava para traficantes. Fora da prisão, não estava fazendo pré-natal. Ao chegar ao CRGPL, foi para o HSF fazer um exame ultrassom e o feto estava com baixo-peso. Sua mãe mandou um Sedex com seus pertences. Joana conta que moram longe e por isso não vêm realizar visita. Conta também que, na gestação anterior, esteve no CRGPL e teve assistência pré-natal e parto com enfermeiras do Hospital. Teve todos os cuidados necessários, como fralda descartável; as outras coisas, a família traz nas visitas. Quando chegam as doaçôes, estas são para todas as presas. Ela relata que fazia a limpeza das áreas comuns e banheiros, lavava roupa. Atualmente, ajuda a cuidar das crianças nos momentos que as mães estão fazendo outras atividades, como oficina de construção de móveis. (Diário de Campo, 16/10/2015).

Simone foi presa com o namorado em sua cidade natal (274 Km de Belo Horizonte); ficou 21 dias numa penitenciária local e foi transferida para o CRGPL aos 6 meses de gravidez. Realizava acompanhamento do pré-natal quando estava na rua. Relata que, quando chegou, gostaria que tivessem realizado um ultrassom, mas não foi feito. Relata que passou mal e foi encaminhada para o Hospital, onde teve o filho de parto normal e retornou no dia seguinte. Atualmente está no "resguardo" e não pode trabalhar, apenas fazer a faxina do alojamento. Relata que cada uma lava sua roupa e cuida do seu filho. Hoje, o filho está com um mês, e depois as cuidadoras (gestantes) ficam com o neném para a gente trabalhar. A família veio em uma visita assistida que dura 40 minutos uma vez. Relata que fica à vontade no pátio junto com outras gravidas e crianças. Aos cinco meses, iniciam a mamadeira e o café da manhã para as crianças, com a rotina de fruta, almoço, café e jantar. Relata que, para o registro de nascimento da criança, a assistente social mandou para o presídio que ele está para reconhecimento e retorno para levar ao cartório. (Diário de Campo, 16/10/2015). 
Analisando a trajetória de vida dessas mulheres, tornou-se possível identificar que a situação de vulnerabilidade, fragilização e precariedade é reforçada pelo encarceramento, o que torna ainda mais difícil que as escolhas sobre o cuidado desejado por elas sejam feitas e discutidas com os profissionais de saúde, tais como garantir continuidade do cuidado no seu território ou mesmo discutir sobre o pedido de um exame específico, como, por exemplo, a realização de ultrassom em alguma etapa do pré-natal. Justamente, foi ao percorrer essas trajetórias que pudemos evidenciar elementos de uma "luta" por reconhecimento, na qual mulheres em situação de privação de liberdade demandam práticas cuidadoras singulares.

De acordo com o referencial proposto por Honneth (2003), o primeiro plano do reconhecimento está relacionado à autoconfiança e se desenvolve por meio das relaçóes de amor. Ou seja, é por meio das relações intersubjetivas de amor que se atualiza o jogo de dependência/autonomia que faz com que o sujeito tenha a confiança básica em si mesmo e no mundo. Dessa forma, para Honneth (2003, p. 164), a relação amorosa é vista "como um processo de reconhecimento mútuo". Martins (2009), ao fazer a analogia desse plano na área da saúde, identifica que essa categoria está relacionada às relações dos profissionais entre si e destes com os usuários, e tem semelhança com a ideia de acolhimento. Miranda et al. (2012) seguem a mesma perspectiva, identificando esse plano com a ideia de "vínculo". Ou seja, o plano poderia ser composto por diversas dimensões onde haveria o reconhecimento de um certo "saber-fazer" pelos profissionais, relacionado a qualidades, exigências e necessidades dos usuários (MIRANDA; RIVERA; ARTMANN 2012).

Nas entrevistas com profissionais, gestores e mulheres, verificou-se que, mesmo na situação de encarceramento, a garantia ao direito à saúde demanda o reconhecimento e a construção de cuidados específicos compartilhados por trabalhadores e gestores junto às mulheres, que vão desde a chegada ao hospital até o pós-parto no CRGPL. Foi relatado que, ao chegar ao hospital para ser examinada, a mulher tem "prioridade" na avaliação no pronto-atendimento, já que vem acompanhada por escolta, muitas vezes com armas. Isso acaba gerando curiosidade nos acompanhantes das outras mulheres presentes na recepção e a expõe a situações constrangedoras. Da mesma forma, assim que ela é internada até o momento da alta, não permanece algemada e faz uso da camisola habitual da instituição; apenas usa o uniforme do sistema prisional no momento da alta. 
Tanto por questôes de segurança mas, principalmente, para maior privacidade, os profissionais informaram que é dada preferência a enfermarias menores, onde o quarto é dividido com as agentes penitenciárias e mais uma família. Observouse que se trata de negociações e pactuações dos trabalhadores de ambas as instituições com essas mulheres, como pode ser identificado na fala de uma enfermeira obstetra:

Quando elas começaram a vim para cá [HSF], elas vinham algemadas e para a gente foi uma agressão ver uma mulher amamentando algemada, então as equipes da Psicologia e Serviço Social ajudaram e a gente conseguiu que elas não ficassem mais algemadas. Hoje elas comem lá no refeitório com a gente, vão à reunião de orientação, participam do cotidiano da instituição. (Enfermeira Obstetra/HSF).

Ao mesmo tempo, pareceu evidente que o agente penitenciário, para trabalhar nessa lógica de cuidado específico, deve ter características peculiares, distintas das encontradas em presídios masculinos e mistos, já que não existem grades nas enfermarias e elas têm liberdade de circular internamente com seus filhos:

A relação com as internas é de muito respeito e elas nos chamam de senhoras. O trabalho no Centro é muito diferente de outras unidades como a penitenciária masculina em que fiquei anteriormente, que somos totalmente isoladas dos presos. [...] O dia a dia é muito próximo e é evidente a construção de um vínculo com a mãe e a criança. Aqui, temos que ver a situação da presa-mãe e filho e nos outros presídios apenas da presa. (Agente Penitenciária/CRGPL).

Existe envolvimento afetivo devido ao corpo a corpo entre as agentes e as mulheres e seus filhos. No momento do parto, as agentes é que são a família. O perfil das mulheres do CRGPL não foge do padrão [do sistema prisional], o que muda é que nesse momento elas estão grávidas. (Psicóloga/CRGPL).

Eu não sinto diferença no tratamento, elas são tranquilas. Quando a gente passa mal elas ficam doidinhas [agentes penitenciárias]. É diferente da outra penitenciária. O tratamento é mais calmo, não tem gritaria. [...] É tranquila a relação com a agente no momento do parto. As agentes têm afinidade com as enfermeiras. (Gestante privada de liberdade/CRGPL).

Aqui, as presas são chamadas de internas, nos outros presídios, de presas. Nas outras penitenciárias, nós [profissionais de saúde] não temos muito contato com elas. Aqui acaba tendo uma proximidade, são chamadas pelo nome, até porque ficam muito tempo. (Técnica de Enfermagem/CRGPL)

Existe um perfil de agente para estar nesse espaço [CRGPL] que é capacitado e consegue acompanhar as mulheres nos seus sintomas no dia a dia. Elas têm a questão da disciplina, mas o trato mais próximo com a interna é importante (Diretora/CRGPL). 
Assim como constatado por Miranda, Rivera e Artmann (2012), a luta por reconhecimento nas relações estabelecidas por essas mulheres e profissionais é considerada fonte de autoconfiança não só para estes, como para elas. Para Martins (2009), a construção da cidadania a partir da perspectiva do reconhecimento está relacionada à esfera da afetividade, que se revela como atitude diante de vivências do cuidado humanizado e da visibilidade pela qualidade do acolhimento pelos profissionais de saúde no atendimento às demandas específicas dessas mulheres. Isso permite que, para além das capacidades técnicas esperadas para cada profissional de saúde ou do sistema prisional, exista o reconhecimento das singularidades dessas mulheres, cotidianamente construídas por elas próprias, trabalhadores e gestores.

O autorrespeito, segundo plano da trilogia proposta por Honneth (2003), está nas relações de direito pautadas nos princípios universalistas que se desenvolveram na modernidade, por meio das lutas de reconhecimento travadas para a construção dos direitos civis, políticos e sociais, todos voltados para a configuração dos cidadãos com igual valor (MENDONÇA, 2007). Na releitura de Martins (2009), o critério central para organização da cidadania estaria relacionado à efetivação dos direitos pelos usuários. Para Miranda, Rivera e Artmann (2012), esse plano está vinculado à ordem social, que se refere à relação da equipe com o serviço e de ambos com os usuários, relativa à esfera dos direitos que reforçam a perspectiva de humanização dos serviços de saúde.

Nas entrevistas, esse plano foi identificado no discurso dos diretores das duas instituições e nas falas dos profissionais do sistema prisional e da saúde, nos quais existe o entendimento de que as mulheres privadas de liberdade perderam um de seus mais importantes direitos civis, relacionado à liberdade de ir e vir. Entretanto, a saúde como um direito lhes deve ser garantida:

Com as mulheres privadas de liberdade, nós aprendemos que elas só perderam o direito de ir e vir, todos os outros [direitos] constitucionais elas têm. (Diretor do HSF).

Aqui [CRGPL] há o entendimento de que elas estão cumprindo com a pena imposta pelo Estado, mas que elas e seus filhos são dignos de um tratamento adequado dentro das possibilidades do sistema prisional. (Diretora CRGPL).

Pareceu-nos evidente que o atendimento à busca de um cuidado na perspectiva da integralidade circunscreve-se, cotidianamente, "dentro das possibilidades do sistema prisional”. Ou seja, o sistema prisional é o espaço onde a mulher não 
tem autonomia para fazer suas escolhas e cuja trajetória de cuidado é definida antes pela lógica desse sistema, que preza pela segurança, em vez de propiciar um diálogo sobre as possibilidades de abertura, como a manutenção dos vínculos familiares, em especial no momento do parto.

Estudo conduzido por Martins et al. (2014) sobre o direito à saúde em uma penitenciária masculina de Minas Gerais verificou que as pessoas privadas de liberdade, ao terem acesso à saúde, eram consideradas privilegiadas. Diferentemente, neste estudo, identificou-se, na entrevista com a agente prisional, que no treinamento introdutório para o exercício da função junto a essas mulheres, essa questão já era abordada: "fomos instruídas sobre os direitos humanos e que as mulheres estão naquele local para cumprirem pena e que não é necessário criar situações de constrangimento ainda maiores" (Agente Penitenciária do CRGPL).

Mais do que o acesso a serviços de saúde, a pessoa privada de liberdade deve ser vista como um indivíduo em suas múltiplas dimensões, cujos direitos fundamentais devem ser garantidos e que, mesmo encarcerado, não deveria ter negado seu direito à autonomia e à iniciativa, em especial no que se refere à sua saúde (LAROUZÉ, 2015). Dessa forma, o atendimento prestado por um profissional de saúde não deve ser considerado um favor ou privilégio, já que a saúde é um direito de todos, inclusive daqueles que foram privados de seus direitos civis e políticos até o cumprimento da pena (SILVA, 2015).

Ao se considerar a perspectiva da integralidade, defendemos a ideia do cuidado como direito de ser; a liberdade de expressar suas demandas não deve se reduzir apenas ao acesso a tecnologias médicas, mas respeitar sua singularidade de existir no mundo, considerando questóes de gênero, raça, orientação sexual, etnia, religiosidade e desabilidades (PINHEIRO, 2010). Pensar na construção desse cuidado requer extrapolar as explicações advindas de conhecimentos disciplinares e fragmentados, no sentido de considerar todos esses aspectos como ações de uma justiça restaurativa, de modo a gerar penas alternativas que permitam criar uma rede de apoio para a mulher privada de liberdade (CERNEKA, 2009).

Essa relação também se estende para a comunidade, que cobra eficiência, para que o direito dessa mulher seja garantido com dignidade, como pode ser observado na fala do diretor sobre o momento em que essas mulheres começaram a ser atendidas no hospital. Até então, havia a cultura de que deveriam permanecer 
algemadas, o que indignou a comunidade local e gerou novos acordos, segundo

os quais a efetivação do direito da mulher não pode ser desvinculada da humanização do atendimento e novas práticas de cuidado em saúde.

[....] As primeiras mulheres que trouxeram aqui, as agentes penitenciárias saiam para fumar algemavam a mulher, saiam para fazer xixi, algemava a mulher e aí queria bater papo lá fora, algemava a mulher, eles algemavam a mulher que estava em aleitamento materno. A associação comunitária chamou a imprensa toda de Belo Horizonte para mostrar como que as mulheres estavam sendo tratadas e deu uma repercussão danada, chegamos em um acordo, nesse acordo que chegou iria evitar de algemar as mulheres e os agentes tinham o direito de fazer isso, então eles iriam mandar duas agentes [....] (Diretor do HSF).

Para Miranda, Rivera e Artmann (2012), nesse plano, a garantia dos direitos deve incluir o interesse do usuário que está na base da relação de acolhimento nos serviços de saúde.

A autoestima constitui o terceiro plano da teoria do reconhecimento de Honneth (2003) e se dá pelo domínio das relações de solidariedade que propiciam algo além do respeito universal. Essas relações acontecem no interior de uma comunidade que compartilha quadros de significação de valores. $\mathrm{Ou}$ seja, diz respeito ao reconhecimento de que os outros parceiros da interação têm características diferenciais que contribuem para a promoção de certos valores reconhecidos no coletivo (MATTOS, 2006). Nas sociedades modernas, "as relações de estima social estão sujeitas a uma luta permanente, na qual os diversos grupos procuram elevar, com os meios da força simbólica e em referência às finalidades gerais, o valor das capacidades associadas a sua forma de vida" (HONNETH, 2003, p. 207).

Para Martins (2009), esse plano está relacionado à resolutividade dos serviços de saúde e à eficácia social e política da garantia do direito à saúde, que se identificaria pela visibilidade por meio da ideia de atenção e pelos modos de funcionamento das referencias e contrarreferências.

Nesse aspecto, Ventura, Simas e Larouzé (2015) constatam que a construção de políticas públicas tem avançado na garantia da integralidade do cuidado a essas mulheres. Observa-se que a construção do projeto de cuidado do CRGPL e suas parcerias atribui um valor social à proposta de cuidado dessas mulheres, como pode ser identificado no discurso de uma profissional que está envolvida desde o início das atividades: 
O centro de referência é uma unidade diferenciada. A maioria dos presídios são mistos. Em 2009, foi feito um projeto do centro de referência. [...] Segue os protocolos relacionados à saúde, especificamente a amamentação e o vínculo mãe-bebê. Aqui, é considerado pela normatização da secretaria estadual como um hospital [....]. Com isso, há uma diferença no olhar. A ideia do projeto era humanizar o atendimento. Inicialmente, uma porcentagem dos agentes precisava ser técnicos de enfermagem. Com o passar do tempo, esse critério foi se perdendo. O mais importante é que a essência se mantém (equipe multiprofissional, cuidado diferenciado...) [...] . Aqui, mais de 70\% das mães vão embora com o bebê. Quando a mãe não sai com o bebê é porque ela continuará presa ou quer doar o filho, e ele só sai com a guarda judicial. Em seis anos e meio, passaram 730 mulheres, sendo que $71 \%$ saíram com seus filhos e quatro foram encaminhados para processo de adoção por desejo materno (Psicóloga/CRGPL).

Constatamos em nossa análise um conjunto de evidencias que apontam para "supervalorização" do papel da maternidade no processo de ressocialização da mulher no CRGPL. Observamos nos relatos das profissionais a importância da maternidade para garantir o sucesso da vinculação da mulher com seu filho, o que reforça a conformação do papel social esperado como adequado para essas mulheres, que tem como base as diferenças biológicas em relação ao homem, o que serve para a naturalização do papel social de mãe nesse espaço.

Como preconizado na legislação, o Núcleo de Atendimento à Saúde interno possui técnico de enfermagem 24 horas, enfermeira de segunda a sexta, odontólogo, médico clínico geral e pediatra duas vezes por semana, contando também com psicóloga e assistente social. No projeto inicial, todas as agentes penitenciárias eram também técnicas de enfermagem. Atualmente, o número de agentes com esse tipo de qualificação diminui bastante; entretanto, todas recebem capacitação para identificar os sinais de alerta da gestação e parto. Os atendimentos de pré-natal de risco habitual são realizados pela enfermeira obstetra do HSF, assim como o acompanhamento de crescimento e desenvolvimento do recém-nascido é realizado por profissionais da enfermagem, fisioterapia e terapia ocupacional do HSF.

Ao mesmo tempo, a unidade conta com uma rede externa de apoio para o atendimento dessas mulheres, descrito da seguinte forma pela técnica de enfermagem:

A rede de serviços de Vespasiano também é referência, além do Hospital Risoleta Neves e Sofia Feldman. A Unidade de Pronto-Atendimento de Vespasiano e a Unidade Básica (para as vacinas). Se a criança precisa internar, se não tem como esperar uma avaliação do pediatra, enviamos para a UPA e, de lá, ele é transferido. A mãe vai 
junto, assim como o agente (2 agentes para uma mãe). [...] Atualmente, os exames são

coletados no pronto-atendimento do município. Agora, as coletas de exame e vacinas dos bebês estão sendo realizadas no próprio presidio. Para isso, a equipe está sendo capacitada. O pré-natal de risco é feito em parceria com uma faculdade privada do município que tem o curso de Medicina (19 gestantes ao todo). E para quem é HIV-positiva, acontece no Orestes Diniz, que é a referência. (Técnica de Enfermagem/ CRGPL).

Dessa forma, podemos inferir, na perspectiva de Honneth (2003), que existe uma rede de solidariedade e compromisso construída pelos trabalhadores no plano estatal com a proposta de criação do CRGPL. Os parceiros de instituições no âmbito municipal e filantrópico compartilham a questão central do direito à saúde dessas mulheres, de forma que sua resolutividade, referência e contrarreferência, de acordo com suas especificidades, são capazes de garantir o direito à saúde e a integralidade do cuidado.

\section{Considerações finais}

Diante dos relatórios e estudos sobre a situação de vulnerabilidade e inviabilidade vivida por mulheres em situação de privação de liberdade, a pesquisa buscou discutir, a partir do referencial da teoria do reconhecimento de Honneth (2003) e de releituras dessa temática no campo da Saúde Coletiva (MARTINS, 2009; MIRANDA; RIVERA; ARTMANN, 2012), uma experiência de cuidado prestada a mulheres de um Centro de Referência de Minas Gerais.

Espera-se que a nova perspectiva de leitura do contexto vivido por essas mulheres e trabalhadores permita colaborar para a identificação de novas formas de cuidado, permeadas de conflitos e consensos, mas também da possibilidade de essas mulheres se reconhecerem como usuárias na relação de cuidado com os profissionais. Nessa linha, a garantia do direito à saúde na perspectiva da integralidade pode trazer elementos que qualifiquem o atendimento e proponham mudanças dos paradigmas presentes nos contextos de encarceramento por meio de práticas de solidariedade.

Entretanto, apesar de as especificidades de gênero no cuidado a essas mulheres estarem presentes nessa experiência, algumas questôes merecem aprofundamento, como o exercício da "maternidade" nesses locais como o principal componente de seu processo de ressocialização. 
A análise do cuidado dessas mulheres a partir de outros referenciais (HONNETH, 2003; MARTINS, 2009; MIRANDA; RIVERA; ARTMANN, 2012) busca dar visibilidade às formas de cuidado mais solidárias, em que a garantia à saúde e a um cuidado integral não seja apenas o cumprimento de um direito individual, mas uma nova forma de tratar a questão junto à sociedade. ${ }^{3}$

\section{Referências}

ANDRADE, V. R. P. A soberania patriarcal: o sistema de justiça criminal no tratamento da violência sexual contra a mulher. Revista Brasileira de Ciências Criminais, n. 48, p. 260-290, maio/junho, 2004.

AYRES, J. R. de C. M. et al. O conceito de vulnerabilidade e as práticas de saúde. In: CZERESNiA, D.; FREITAS, C. M. (Org.) Promoção da saúde: conceitos, reflexões e tendências. 2. ed. Rio de Janeiro: Editora Fiocruz, 2009. p. 121- 143.

BRASIL. Congresso Nacional. Câmara dos Deputados. Comissão Parlamentar de Inquérito do Sistema Carcerário. CPI sistema carcerário. - Brasília: Câmara dos Deputados, Ediçôes Câmara, 2009 (Série Ação Parlamentar; n. 384).

- Ministério da Justiça. Departamento Penitenciário Nacional. Levantamento nacional de informaçôes penitenciárias: INFOPEN - junho de 2014. Brasília: Ministério da Justiça, 2014a.

Ministério da Saúde. Portaria Interministerial n. 1, de 2 de janeiro de 2014.

Institui a Política Nacional de Atenção Integral à Saúde das Pessoas Privadas de Liberdade no Sistema Prisional (PNAISP) no âmbito do Sistema Único de Saúde (SUS). Diário Oficial da República Federativa do Brasil. Brasília: Ministério da Saúde. 2014 b.

Ministério da Saúde. Secretaria de Atenção em Saúde. Departamento de Ações Programáticas Estratégicas. Legislação em saúde no sistema penitenciário. Brasília: Ministério da Saúde, 2010.

Presidência da República. Secretaria Especial de Políticas para as Mulheres. Grupo de Trabalho Interministerial. Reorganização e reformulação do sistema prisional feminino: relatório final. Brasília: Secretaria Especial de Políticas para as Mulheres, 2008.

. Presidência da República. Casa Civil. Subchefia para Assuntos Jurídicos. Lei n. 11.942, de 28 de maio de 2009. Dá nova redação aos arts. 14, 83 e 89 da Lei no 7.210, de 11 de julho de 1984 - Lei de Execução Penal, para assegurar às mães presas e aos recém-nascidos condições mínimas de assistência. Diário Oficial da União, Brasília, DF, 29 maio 2009.

CARVALHO, M. L. et al. Perfil dos internos no sistema prisional do Rio de Janeiro: especificidades de gênero no processo de exclusão social. Ciência \& Saúde Coletiva, v. 11, n. 2, p. 461-471, 2006. 
CERNEKA, H. A. Homens que menstruam: consideraçôes acerca do sistema prisional às especificidades da mulher. Veredas do Direito, Belo Horizonte, v. 6, n. 11, p. 61-98, jan./jun. 2009.

CENTRO PELA JUSTIÇA E PELO DIREITO INTERNACIONAL et al. Relatório sobre mulheres encarceradas no Brasil. 2007. Disponível em: <http://www.asbrad.com.br/ conte\%C3\%BAdo/relat\%C3\%B3rio_oea.pdf>. Acesso em: 03 jan. 2016.

CONSELHO NACIONAL DE POLÍTICA CRIMINAL E PENITENCIÁRIA. Resolução no 07, de 14 de abril de 2003. Firma diretrizes básicas para as ações de saúde nos sistemas penitenciários. Diário Oficial da União, Brasília, DF, 24 abr. 2003.

COUTINHO, F. M. M. et al. O cuidado de mulheres privadas de liberdade e seus filhos: percursos e mediações necessárias de gestores e trabalhadores para a garantia do direito à saúde dessa população. In: PINHEIRO, R. et al. (Org.). Cultura do Cuidado e o cuidado na cultura: dilemas, desafios e avanços para a efetivação da integralidade em saúde no Mercosul. Rio de Janeiro: CEPESC/IMS-UERJ/ABRASCO. 2015. p. 199-210.

GOIS, S. M. et al. Para além das grades e punições: uma revisão sistemática sobre a saúde penitenciária. Rio de Janeiro. Ciência e Saúde Coletiva, v. 17, n. 5, p. 1235-1246, 2012.

HONNETH. A luta por reconhecimento: a gramática moral dos conflitos sociais. São Paulo: Editora 34, 2003.

JESUS, L. O.; LERMEN, H. S. Mulheres e políticas de saúde no sistema prisional do Rio Grande do Sul. In: SEMINÁRIO INTERNACIONAL FAZENDO GÊNERO. 10. 2013, Florianópolis. Anais Eletrônicos... Florianópolis: [s.n.], 2013, p. 1-11. Disponível em: <http://www.fazendogenero.ufsc.br/10/resources/anais/20/1386686774_ARQUIVO_ LucianaOliveiradeJesus.pdf. >. Acesso em: 06 jan. 2016.

LAROUZÉ, B. Prefácio. In: SILVA, M. Saúde penitenciária no Brasil: plano e política. Brasília: Verbena, 2015. P.8-10.

MARTINS, E. L. C. et al. O contraditório direito à saúde de pessoas em privação de liberdade: o caso de uma unidade prisional de Minas Gerais. Saúde Soc. São Paulo, v. 23, n. 4, p. 1222-1234, 2014

MARTINS, P. H. Fundamentos da cidadania na saúde na perspectiva do reconhecimento: caminhos da pesquisa. In: PINHEIRO, R.; MARTINS, P. H. (Org.) Avaliação em saúde na perspectiva do usuário: abordagem multicêntrica. Rio de Janeiro: CEPESC, 2009. p. 131-138. MATTOS, P. A sociologia política do reconhecimento: as contribuiçôes de Charles Taylor, Alex Honneth e Nancy Fraser. São Paulo: Annablume, 2006

MENDONÇA, R. F. Reconhecimento em debate: os modelos de Honneth e Fraser em sua relação com o legado habermasiano. Rev. Sociol. Polit., n. 29, p. 169-185, 2007. 
MINAS GERAIS. Secretaria de Estado de Defesa Social. Centro de referência à gestante privada de liberdade amplia capacidade com inauguração de nova ala. Belo Horizonte: Secretaria de Estado de Defesa Social, 2011. Disponível em: <http://www.seds.mg.gov.br/ component/gmg/story/1363-centro-de-referencia-a-gestante-privada-de-liberdade-ampliacapacidade-com-inauguracao-de-nova-ala>. Acesso em: $28 \mathrm{dez} .2015$.

MINZON, C. V; DANNER, G. K; BARRETO, D. J. Sistema prisional: conhecendo as vivências da mulher inserida neste contexto. Akrópolis, Umuarama, v. 18, n. 1, p. 71-81, jan./mar. 2010.

MIRANDA, L.; RIVERA, U.; ARTMANN, E. Trabalho em equipe interdisciplinar de saúde como um espaço de reconhecimento: contribuições da teoria de Axel Honneth. Physis: Revista de Saúde Coletiva, v. 22, n. 4, p. 1563-1583, 2012.

MIYAMOTO, Y.; KROHLING, A. Sistema prisional brasileiro sob a perspectiva de gênero: invisibilidade e desigualdade social da mulher encarcerada. Direito, Estado e Sociedade. n.40, p. 223- 241, jan/jun, 2012.

PINHEIRO, R. As práticas do cotidiano na relação oferta e demanda dos serviços de saúde: um campo de estudo e construção da integralidade. In: PINHEIRO, R.; MATTOS, R. A. de (Org.). Os sentidos da integralidade na atenção e no cuidado à saúde. 3. ed. Rio de Janeiro: IMS-UERJ, 2001. p. 65-112.

Cuidado como valor: um ensaio sobre o (re)pensar e a ação na construção de práticas eficazes de integralidade em saúde. In: PINHEIRO, R.; MATTOS, R.A. de (Org.). Razóes públicas para a integralidade em saúde: o cuidado como valor. Rio de Janeiro: Cepesc, 2007. p. 15-28.

. Demanda por cuidado como direito humano à saúde: um ensaio teórico-prático sobre o cuidado como valor dos valores. In: PINHEIRO, R.; SILVA JUNIOR.; A. G. (Org.). Por uma sociedade cuidadora. Rio de Janeiro: CEPESC-IMS/UERJ-ABRASCO, 2010.

PINHEIRO, R.; SILVA JUNIOR; A. G. da. Práticas avaliativas e as mediações com a integralidade em saúde: uma proposta para estudos de processos avaliativos na atenção básica. In: (Org.). Atenção básica e integralidade: contribuições para estudos de práticas avaliadoras em saúde. Rio de Janeiro: CEPESC-IMS/UERJ-ABRASCO, 2011.

RODRIGUES, A. S. Raça, gênero e sistema prisional: relato de experiências com mulheres negras que cumprem penas em regime aberto ou semiaberto. Revista África e Africanidades, v. 1, n. 3, nov. 2008 .

SILVA, M.. Saúde penitenciária no Brasil: plano e política. Brasília: Verbena, 2015. 120p.

SCHUTZ, A. Relações interativas. In: WAGNER, H. (Org.). Fenomenologia e relaçôes sociais: textos escolhidos de Alfred Schutz. Rio de Janeiro: Zahar, 1979. p. 159-195.

VENTURA, M.; SIMAS, L.; LAROUZÉ, B. Maternidade atrás das grades: em busca da cidadania e da saúde. Um estudo sobre a legislação brasileira. Cad. Saúde Pública, Rio de Janeiro, v. 31, n. 3, p. 607-619, mar 2015. 
${ }^{1} \mathrm{O}$ uso do termo "vulnerabilidade" designa grupos ou indivíduos fragilizados, jurídica ou politicamente, na garantia, promoção e proteção dos seus direitos de cidadania (AYRES et al., 2009).

${ }^{2}$ Honneth (2003) emprega o termo "amor" da forma mais neutra possível. Para o autor, por relações amorosas devem ser entendidas todas as relaçōes primárias, na medida em que elas consistam em relaçôes emotivas fortes entre poucas pessoas, segundo o padrão de relaçôes entre dois parceiros, de amizade e de relações pai/filho (HONNETH, 2003, p. 159).

${ }^{3}$ T.C. Lopes trabalhou na concepção, elaboração e revisão final. R. Pinheiro colaborou na concepção, elaboração e revisão final do artigo. 


\section{Abstract}

Trajectories of women deprived of freedom: health care practices in the recognition of the right to health in a Reference Center of Minas Gerais State, Brazil

Objective: To analyze the care trajectory of women in a Reference Center to Pregnant Women Deprived of Liberty (CRGPL), regarding the practices of workers in the recognition of the right to health and integral care to women and newborns. Methodology: As reference, the sociological phenomenology and the theory of recognition proposed by Alex Honneth were adopted. Women, prison officers, CRGPL directors, Sofia Feldman Hospital managers and health professionals of both institutions were interviewed. Also, it was held direct observation of meetings between the two directors.

Results and Discussion: Three recognition plans proposed by Honneth were identified. Self-confidence was observed in bond and acceptance relationships of these women by managers and workers. Self-respect was identified in the awareness, by professionals and managers, that these women lost their civil rights, but that health as a right should be guaranteed. There was self-esteem in the network of solidarity and commitment, so that resolution, reference and counter-reference for these women and their children ensure the right to health and integral care. Conclusions: The study seeks to give visibility to forms of more supportive care, that ensuring health and comprehensive care is not only the fulfillment of an individual right, but a new way to handle this issue in society.

> Keywords: pregnant women; prison; health integral care. 